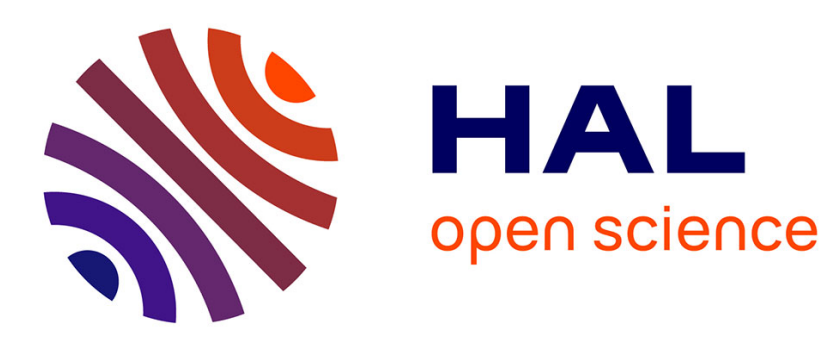

\title{
Destination performance: Introducing the utility function in the Mean-Variance space
}

\author{
Linjia Zhang, Laurent Botti, Sylvain Petit
}

\section{To cite this version:}

Linjia Zhang, Laurent Botti, Sylvain Petit. Destination performance: Introducing the utility function in the Mean-Variance space. Tourism Management, 2016, 52, pp.123-132. hal-01831499

\author{
HAL Id: hal-01831499 \\ https://hal.science/hal-01831499
}

Submitted on 5 Jul 2018

HAL is a multi-disciplinary open access archive for the deposit and dissemination of scientific research documents, whether they are published or not. The documents may come from teaching and research institutions in France or abroad, or from public or private research centers.
L'archive ouverte pluridisciplinaire HAL, est destinée au dépôt et à la diffusion de documents scientifiques de niveau recherche, publiés ou non, émanant des établissements d'enseignement et de recherche français ou étrangers, des laboratoires publics ou privés. 


\section{Destination performance: Introducing the utility function in the Mean-Variance space}

L. Zhang (Associate Professor, Heilongjiang University, zhanglinjia@hlju.edu.cn)

L. Botti (Associate Professor, CRESEM-CAEPEM, IAE de l'UPVD, laurent.botti@univ-perp.fr)

S. Petit (Associate Professor, GDI, University of French Polynesia, Associate Researcher, IDP, Univ. of Valenciennes)

(Reference: Zhang L., Botti L. \& S. Petit (2016), « Destination performance: Introducing the utility function in the Mean-Variance space », Tourism Management, vol.52, p123-132) 


\begin{abstract}
Economic characteristics of home countries can cause considerable variations in the tourism demand. For example, the average level of expenditure per tourist varies from one origin to another and these variations may alter overtime. Thus different tourist nationalities are associated with different level of expenditures and risks. Therefore strategies aimed at minimizing the variations may become an important issue for the policy makers. In this paper, we aim to use the productivity measurement theory in a mean-variance space to a French region (Nord Pas-de-Calais) by introducing the utility function in a mean-variance framework. With this method, we can calculate the optimal portfolio share for each origin and give some useful political advices to the policy decision makers to improve the performance of the tourist sector.
\end{abstract}

Keywords: Productivity Measurement ; Mean-Variance ; Tourism Efficiency ; Efficiency Decomposition ; Utility Function ; Nord Pas-deCalais.

JEL Code: L83, C61, C67 


\section{Introduction}

Tourism is an important Industry in the French region of Nord Pas-deCalais (NPDC). Given its favourable location in the heart of North-East Europe, in the middle of London-Paris-Brussels triangle, NPDC receives over 175 million trips per year. In order to take full advantage of this industry to strengthen the local economy, actions are being implemented to further develop regional tourism. The Eurostar and Thalys high-speed train make Lille, the capital of NPDC ever closer to London and Brussels. Development of Lille Airport connect the region to other major markets such as Barcelona, which is now only two hours away by flight even more accessible. .

In terms of employment, tourism generated an average of nearly 39,000 salaried jobs in 2009 for the NPDC, representing an increase of $16 \%$ compared to 2003. This job places creation allows NPDC to rank only ninth at regional level. However, compared to the national average which is $4.8 \%$, the tourism employment represents only $2.7 \%$ of salaried jobs in this region ${ }^{1}$. In terms of tax revenue, tourism is a springboard for the economy of the region. Indeed, tourism and leisure represent $3.30 \%$ of regional GDP in 2009, equivalent to the compulsory residence permit paid by the locals and amounting to 3.5 million euros. Nevertheless, the economic contribution from the tourism sector in this region is lower than the average French level as tourism represents more than $6.5 \%$ of the national GDP. There is room for improving the efficiency of the tourism industry of in order to increase the economic contribution of the sector of tourism in this region of France. The region Nord Pas-de-Calais represents only $0.2 \%$ of the total national investment in tourism. The local authorities have understood the economic potential from tourism. Since the beginning of

\footnotetext{
${ }^{1}$ All numbers above comes from the French National Institute of Statistical and Economic Study
} 
the 2000s, the local authorities had invested in the organization of different business events. More than 55\% of tourists are professional customers. The advantage of this strategy is to develop new opportunities of market. If the British is the first foreign market, the local authorities expect to attract another nationalities with the centenary of the $1^{\text {st }}$ World War (Canadian, American and Australian soldiers were present in this region just as well as Chinese workers) and the $70^{\text {th }}$ birthday of the end of the $2^{\text {nd }}$ World War. The geographic localization of the NPDC region can also provide another advantage if it is well exploited.

Authors such as Barros (2004), Barros et al., (2011) and Assaf (2012) have developed efficiency measurement of tourism industry. But very few works have been done on the efficiency measurement following origins of tourists. A viable and resilient tourism destination should try to maximize the number of tourists come from different origins, and minimize the instabilities in revenues by diversifying its market mix (Kennedy, 1998). The efficiency following the tourist's origins is one of the essential questions to understand the composition and characteristics of the local tourism industry. In order to answer this question, the performance evaluation (in terms of possible revenue augmentation and/or possible risk contraction) of inbound tourist is valuable and necessary. The result of this kind of analysis can guide the policy makers by giving them the accurate efficiency indicators for future decision-making process.

The aim of the current paper is to introduce a nonparametric efficiency measurement framework into a mean-variance space, in order to evaluate the performance of tourism sector and identify the possible source of the existing inefficiency. The contribution of this paper is two-fold. First it improves the existing measures of efficiency by introducing the decision maker's utility function; second, the result obtained is used to develop strategies for reducing volatility in tourism receipt. Accordingly, this paper 
proposes a framework for the evaluation of destination performance which can assist Destination Management Organizations (DMO) in enhancing the performance of the industry.

The paper is organized as follows: section 2 critically reviews the existing literature on the measurement the tourism efficiency; section 3 presents our theoretical framework; in section 4, data from NPDC is analyzed using mean-variance method. The paper ends by a discussion of the results and develops a framework for policy makers. .

\section{Efficiency measurement in tourism}

The performance of a firm, particularly as measured by productivity and efficiency, has been a common subject in tourism studies. The hotel sector has attracted the most attentions, followed by travel agents and restaurants. The empirical literature on the effectiveness of the tourism business has been dominated by the non-parametric approach: Data Envelopment Analysis (DEA; Seiford, 1996).

The first effort of applying DEA to tourism begins in the year 80s. Hruschka (1986a) measured then different Australian restaurant groups and found that there exists difference efficiency among these groups. Banker and Morey (1986b) who introduced quasi-fixed variables in DEA, evaluated the technical and scale efficiency of 60 fast food restaurants with discretional variables. Morey and Dittman (1995) evaluated the performance of 54 hotels of a national chain in the U.S, and found these hotels were quite efficient, with an efficient score of 0.89 . More recent applications include Anderson, Fok and Scott (2000), Hwang and Chang (2003), Barros and Alves (2004), Daniels (2004), Chiang, Tsai and Wang (2004), Barros (2005), Barros and Santos (2006), Köksal and Aksu (2007), Botti et al. (2009), Perrigot et al. (2009), Assaf et al. (2011), Assaf (2012) and many others. However, there are only very few works which have 
studied the tourism sector at a territory level: Bosetti et al. (2006), Peypoch (2007), Barros et al. (2011) and these papers have used basic DEA model (CCR for Charnes et al. (1978) model and/or BCC for Banker et al. (1984) model) as theoretical framework. And only two papers (Botti et al., 2009; Ratsimbanierana et al., 2013) make an efficiency assessment of regions with a directional distance function (DDF - Chambers et al., 1998).

In his paper, theoretical framework applies a nonparametric efficiency measurement, and uses DDF in a mean-variance space to calculate an overall efficiency (OE) indicator, which can be decomposed into a technical efficiency (TE) indicator and an allocative efficiency (AE) indicator. The advantage of this technique is that with consideration of utility function in a Mean-Variance space, we can find out more precisely the source of the inefficiency, thus propose a more appropriate suggestion to the policy decision maker.

To the author's knowledge, there are only two articles (Botti et al., 2012; Ratsimbanierana et al., 2013), which used DDF in a mean-variance framework to measure the destination efficiency according to tourist origins. However, these papers have just measured the technical efficiency and did not attempt to find other kind of inefficiencies in the tourism sector. The next sections of this present article fill this gap in the literature.

\section{Theoretical Framework}

Scarcity of resource and ever growing needs for justifying investment has lead to more and more emphasis being laid on the analysis of the relationship between resources allocation and their economic return. For a given country or region, ways to minimize the instability and maximizing the return of their inbound tourism with consideration of utility function are very important issues for the policy decision makers (Kennedy, 1998; Botti et al., 2012). This idea is very related to the conception of modern 
investment theory. Therefore, the mean-variance space seems a suitable framework in our case.

\subsection{Efficient frontier and portfolio management}

Consider $n$ funds with a return vector $R=\left(R_{1}, R_{2}, \ldots, R_{n}\right)^{\prime}$, each fund is then characterized by an expected return $E\left(R_{i}\right)$ and a variance $V\left(R_{i}\right)$, where $i=1,2, \ldots, n$. Then the expected return vector and the variance vector can be written separately by $E(R)=\left(E\left(R_{1}\right), E\left(R_{2}\right), \ldots, E\left(R_{n}\right)\right)^{\prime} \quad$ and $V(R)=\left(V\left(R_{1}\right), V\left(R_{2}\right), \ldots, V\left(R_{n}\right)\right)^{\prime}$. Then the covariance matrix of these funds can be written by $\Omega_{i j}=\operatorname{COVA}\left(R_{i}, R_{j}\right)$, where $i=1,2, \ldots, n$ and $j=1,2, \ldots, n$. Then we can define a portfolio $X$, which is composed by these $n$ funds, with the vector $x=\left(x_{1}, x_{2}, \ldots x_{n}\right), \sum_{i} x_{i}=1$ indicate the weight of each fund.

The return of portfolio $X$ is $R(X)=x R$. The expected return and its variance can be calculated as follows:

$$
\begin{aligned}
& E(R(X))=x E(R) \\
& V(R(X))=x \Omega_{i j} x^{\prime}
\end{aligned}
$$

If all the constraints faced by the investors for each funds can be written by a linear function of the fund's weight, then the set of possible portfolio is defined as:

$$
\mathfrak{I}=\left\{x \in R^{n}, \sum_{i} x_{i}=1, A x^{\prime} \leq b, x \geq 0\right\}
$$

Then the Markowitz mean-variance space is defined as:

$$
\aleph=\{(V(X), E(X)) ; x \in \mathfrak{I}\}
$$

But from a mathematical point of view, this representation cannot be used directly for quadratic programming (see Briec, Kerstens, and Lesourd (2004)). The above set is then extended by defining a portfolio representation set as: 


$$
\Re=\left\{\left(V^{\prime}, E^{\prime}\right) \in R_{+} \times R ; \exists x \in \mathfrak{I},\left(-V^{\prime}, E^{\prime}\right) \leq(V(X), E(X))\right\}
$$

Then the efficiency frontier is defined as:

$$
\begin{aligned}
\partial(\Im)= & \{(V(R(X)), E(R(X))) ; \\
& \left.x \in \mathfrak{I} \wedge(-V(R(X)), E(R(X)))<\left(-V^{\prime}, E^{\prime}\right) \Rightarrow\left(V^{\prime}, E^{\prime}\right) \notin \mathfrak{R}\right\}
\end{aligned}
$$

This frontier represents the set of all the mean-variance points that are not strictly dominated in the two-dimensional space.

\subsection{Markowitz efficiency frontier}

Markowitz defines an optimization program to determine the portfolio corresponding to a given degree of risk aversion. This portfolio maximizes a mean-variance utility function defined by:

$$
U_{(\rho, \mu)}=\mu E(R(x))-\rho V(R(x))
$$

where $\mu>0$ and $\rho>0$ represent separately the marginal utility for the investors for the expected return and risk. The ratio $=-$ traditionally represents investors' risk aversion. The quadratic program is written as:

$$
\begin{gathered}
U_{(\mu, \rho)}^{*}=\sup \mu E(R(x))-\rho V(R(x)) \\
\text { s.t. } \quad A x^{\prime} \leq \mathrm{b} \\
\sum_{i=1, \ldots, n} x_{i}=1 \\
x \geq 0
\end{gathered}
$$

So given the investors' risk aversion, this program allows one to choose an "optimal" portfolio in the efficiency frontier, which can maximize their utility function. Following Uysal, Trainer, and Reiss (2001), the conventional values for risk aversion $=-$ often range between 0.5 and 10 . 
In this article, $\phi=2$ (with $=2$ and $=1$ ) is used ${ }^{3}$ according to Morey and Morey (1999) and Briec et al. (2004).

\subsection{Efficiency measurement}

The efficiency measurement of a set of decision units (or a portfolio for the Markowitz model) consists in roughly enveloping the data and then measuring the distance between the realized performance of each unit (each portfolio in the Markowitz model) and this estimated frontier. This gap between the unit and the frontier is defined as inefficiency. In fact, the technology is represented by the frontier between feasible and infeasible productions. The frontier itself is important as it contains all the relevant information about marginal productivity, elasticity of substitution and returns to scale; it is not directly observable and must then be estimated. The characterization of the frontier rests on an axiom that provides some indication on expectations from the frontier. This paper proposes to use a directional distance function to measure the inefficiency. The directional distance function measures the distance between the observation and the efficient frontier along a chosen directional vector pre-chosen. This idea was introduced by Luenberger (1992) and has been used in several sectors: Briec et al. (2004) and Briec et al. (2007) suggest an application in the financial sector, as did Peypoch and Solonandrasana (2006) and Peypoch (2007). Botti et al. (2012), and Ratsimbanierana et al. (2013) have already applied DDF in a Mean-Variance framework. However, as we explain at the end of this section, they just measured the technical efficiency in their papers and did not try to find other kind of inefficiency for the tourism sector.

\footnotetext{
${ }^{3}$ A robustness check of our results by testing different values of risk aversion will be presented in the empirical section
} 
Following the demonstration of Briec, Kerstens, and Lesourd (2004), the directional distance efficiency measurement function is defined as:

$$
S_{g}(x)=\sup \left\{\theta ;\left(V(R(x))-\theta g_{V}, E(R(x))+\theta g_{E}\right) \in \mathfrak{R}\right\}
$$

The DDF seeks the greatest possible risk (variance) contraction in the negative direction vector $g_{V}$ in order to obtain the maximum attainable expansion of expected return in the positive direction $g_{E}$.

In summary, this function measures the potential improvement in term of the possible increase in expected return and reduction in variance for a given direction vector $g=\left(-g_{V}, g_{E}\right)$. The advantage of this method compared to the classical DEA model is the possibility to control the projection direction of the inefficient points to the efficient frontier. Morey and Morey (1999) already introduced the DEA model in portfolio efficiency measurement. But their model had two specific perspectives: maximize the expected return for a fixed variance, or minimize the risk for a given expected return. As we can see, their model is just a specific case of the DDF approach (with $g_{V}=0$ or $g_{E}=0$ ). In fact, in their paper, they just used a Shephard's distance function, which is commonly used in the classic DEA models. Among other differences between these two functions (see Färe and Grosskopf, 2000 for detail), one difference is DDF has an additive structure while the other ones are additive by nature.

For the policy makers, not only evaluating the performance of their sector is necessary, but also knowing the sources of its inefficiency is equally or even more important. Here the distinction between allocative, and technical efficiency is proposed when evaluating the scope for improvements of tourism strategies. OE indicator measures the distance between the maximum utility that the portfolio can reach and the current utility for one portfolio normalized by the directional vector. This idea is in fact very similar to the Nerlovian profit indicator. The formulation 
proposed by Chambers et al. (1998b) is followed to calculate this indicator, which allows us to a dual relationship between the Markowitz utility function and the DDF.

For a chosen risk aversion parameters $(\rho, \mu)$, the maximum utility function is defined as $U^{*}() \quad E,(R(x)) \quad V(R(x))$ for $x \in \mathfrak{R}$. This implies that the efficient utility is no less than the value of the feasible meanvariance vector. Thus, for the portfolio $k$, we have the relation:

$$
\begin{aligned}
U_{(\mu, \rho)}^{* k} & \geq \mu\left(E(R(x))+\theta g_{E}\right)-\rho\left(V(R(x))-\theta g_{V}\right) \\
& \geq(\mu E(R(x))-\rho V(R(x)))+\theta\left(\mu g_{E}+\rho g_{V}\right)
\end{aligned}
$$

This function establishes the relationship between portfolio $k$ 's utility function $U_{(\mu, \rho)}^{* k}$ and the DDF. This relation can also be interpreted as the one portfolio's maximal utility is greater than or at least equal to the actual or observed utility, plus the gain in utility resulting from reductions in technical inefficiency. And we have:

$$
\theta=\underset{\mu, \rho}{\operatorname{Max}} \frac{U^{*}(\mu, \rho)-U(\mathrm{x})}{\mu \mathrm{g}_{E}+\rho \mathrm{g}_{V}}
$$

From the portfolio's specific utility function established earlier it can be observed, after the necessary re-arrangement, that a portfolio's utility efficiency or so we called $\mathrm{OE}$ in general can be expressed as: $\frac{U^{*}(\mu, \rho)-U(\mathrm{x})}{\mu \mathrm{g}_{E}+\rho \mathrm{g}_{V}} \geq \theta$

The above inequality is explained by the possible presence of inefficient allocation of resources even when all technical inefficiencies are eliminated, like point $\mathrm{B}$ in the figure 1 . While it is technically efficient for being on the efficient frontier; it is not overall efficient. The presence of inefficient resource allocation in portfolio B is a possible source of its profit inefficiency. The inequality is thus closed when the allocative inefficiency component is added, resulting in equality of the above expression. This 
means that the allocative inefficiency is residually determined from the Nerlovian profit and technical inefficiencies. It should be observed that the elimination of technical and allocative inefficiencies is expected, all else remaining constant, to achieve full efficiency. The equality between the utility, technical, and allocative efficiencies is given by the following expression: $\frac{U^{*}(\mu, \rho)-U(\mathrm{x})}{\mu \mathrm{g}_{E}+\rho \mathrm{g}_{V}}=\theta+A E(\mathrm{x})$

Then the Overall efficiency $(\mathrm{OE})$ is calculated as:

$$
O E(x,,)=\left(U^{*}(, \quad) \quad U(\mathrm{x})\right) /\left(\mathrm{g}_{E^{+}} \mathrm{g}_{V}\right)
$$

Portfolio efficiency indicator (PE) it is called technical efficiency (TE), as in Briec et al. (2007) and is calculated by:

$$
P E(x)=\theta=S_{g}(\mathrm{x})
$$

This indicator measures the possible improvement of a portfolio by projecting it to the efficiency frontier. But it cannot guarantee that the corresponded point on the frontier can maximize the utility function; therefore, this indicator just reflects the technical efficiency.

Allocative efficiency (AE) indicator is calculated:

$$
A E(\mathrm{x})=O E(x, \rho, \mu)-P E(x)
$$

The difference between the $\mathrm{OE}$ and PE gives us an idea about the allocation of resources to funds, taking into account decision maker's preferences. For the production theory, the allocative inefficiency arises from the provision of services in the wrong mix, give their prices, which means the manager has rooms to combine inputs and/or outputs in a better proportions in light of prevailing prices. For the tourism portfolio perspective, it means given the destination's preference of risk, we can change the combinaisons of origins to improve destinations' overall efficiency. If $\mathrm{AE}$ is not equals to zero, we have to move the portfolio along the frontier to achieve the maximum utility function in 
regards prioritization of objectives by the policy maker. The idea is presented in figure 1 and the specification of this function is presented in the next section.

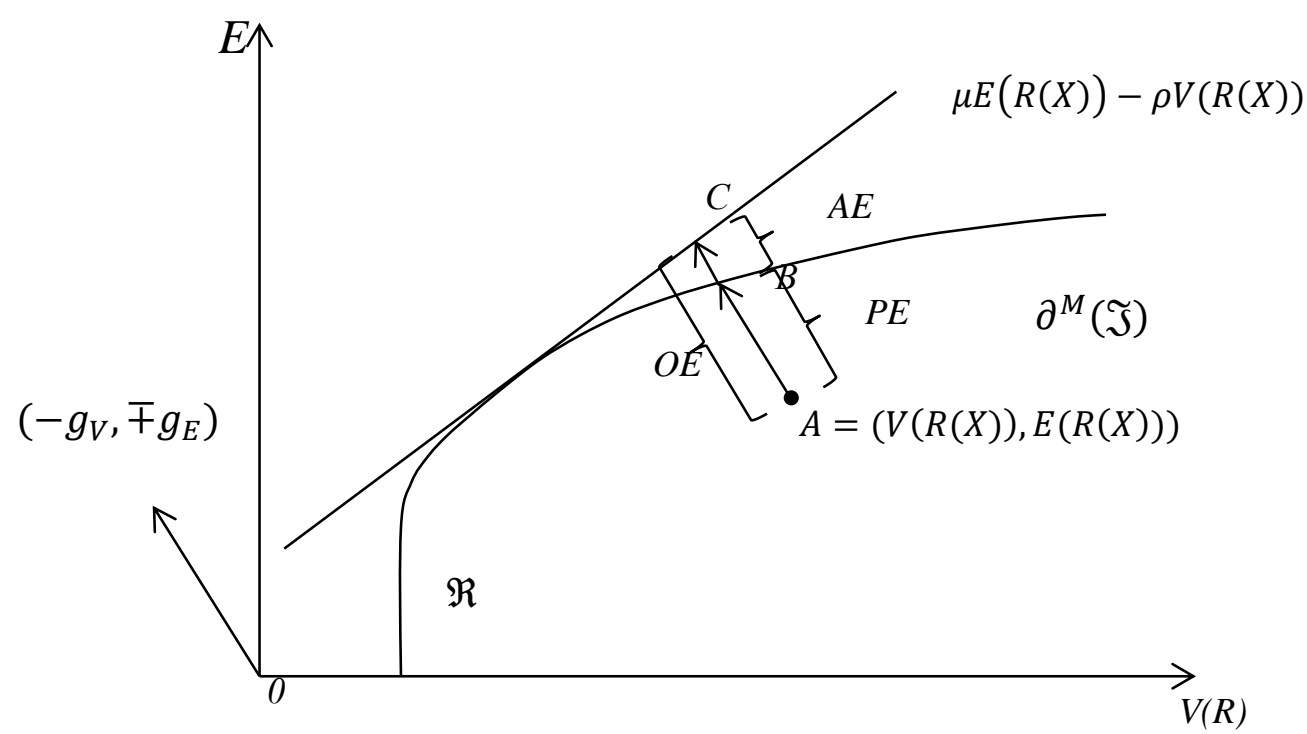

Fig. 1. Markowitz utility function, DDF and inefficiency decomposition

In their paper, Botti et al. (2012) did not take the utility function (presented by the tangent line in Figure 1) into consideration. Therefore, they estimated the efficient frontier in their paper, and calculated PE. By calculating the optimal utility function, our framework is able to estimate the technical efficiency for the tourist origins and assess the possible improvement of decision maker's utility for each origin. The improvement in utility can be further decomposed into technical efficiency improvement and allocative efficiency improvement.

\subsection{Statistic model}

This sub-section presents the statistic model used to calculate OE, PE and $\mathrm{AE}$. In accordance with the non-parametric efficiency measurement theory, the best practical observable points are taken as benchmarks. The definition in Equation 8, leads to the following quadratic program in order to calculate the technical efficiency $\theta_{o}^{P E}$ for the objective origin $R_{o}$ : 


$$
\begin{array}{ll}
\max & \theta_{o}^{P E} \\
\text { s.t. } & E\left(R_{o}\right)+\theta_{o}^{P E} g_{E} \leq x E(R) \\
& V\left(R_{o}\right)-\theta_{o}^{P E} g_{V} \geq x \Omega_{i j} x^{\prime} \\
& \sum_{i=1, \ldots, n} x_{i}=1 \\
& x \geq 0
\end{array}
$$

The overall efficiency $\theta_{o}^{O E}$ is calculated in a 3 steps procedure:

1- Equation (8) is used to obtain $U_{(\rho, \mu)}^{*}$,

2- Equation (14) to obtain $\theta_{o}^{O E}$, and finally

3- The allocative efficiency $\theta_{o}^{A E}$ is calculated as follow:

$\theta_{o}^{A E}=\theta_{o}^{O E}-\theta_{o}^{P E}$

For $n$ origins, we have to repeat $n$ times this process.

It is clear that the risk related parameters $(\mu, \rho)$ will influence the slope of the utility function. Therefore, $\theta_{o}^{O E}$ is variant with $\mu$ and $\rho$. However, since the calculation of $\mathrm{OE}$ is not directly related to risk aversion, $\theta_{o}^{P E}$ should remain invariant to these parameters. As we mentioned above, a robust test of our results by testing different values of risk aversion will be presented at the end of the empirical section of this paper.

\section{An application to Nord Pas-de-Calais (France)}

Instead of using the price of funds as in the traditional financial investment theory, we have to choose a variable, which can represent the value of inbound tourists for the concerned local economy. In the tourism industry, it's not the number of visitors' arrival, which is the most important element for an economy. The expenditure of tourists is a more proper variable to evaluate the contribution of tourism to an economy. However, in our case, only the overnight stays data are available. This variable is commonly used in the literature (see for example Peypoch, 2007 and Botti et al., 2012). Furthermore, it is clear that a tourist who choses to 
stay in a "one star" hotel will normally spend less than a tourist who chose to stay in "five star" hotel. The database for NPDC, includes data on average hotel price of different categories (null and 1 star, 2 star, 3 and 4 star) for 2013, and the number of overnight stays for tourists from different origins in different category hotels. Therefore, monthly data of the overnight stays from 16 different countries is weighted by their hotel rates to take into account different expenditure level. This variable will be used as a proxy of the value of inbound tourist for NPDC. Risk and return are calculated over a 7 years horizon between 2006-2012. The statistical description of our data is presented in table 1 . Table 2 presents the average prices used. 


\section{Table 1}

Statistical description of NPDC tourists monthly overnight stays between 2006 and 2012

\begin{tabular}{|c|c|c|c|c|c|}
\hline Origins & $\overline{\mathrm{N}}$ & Min & Max & Mean & Std \\
\hline $\begin{array}{l}\text { Other European } \\
\text { Countries }\end{array}$ & 84 & 738 & 13370 & 4506.23 & 2436.22 \\
\hline Germany & 84 & 745 & 18313 & 4836.43 & 3434.03 \\
\hline Belgium & 84 & 1387 & 49832 & 11739.12 & 8719.33 \\
\hline Spain & 84 & 196 & 7244 & 1493.25 & 1026.26 \\
\hline Italy & 84 & 275 & 9567 & 2253.16 & 1504.77 \\
\hline Netherlands & 84 & 488 & 18436 & 3797.77 & 3183.94 \\
\hline United Kingdom & 84 & 5247 & 179199 & 45644.03 & 36389.96 \\
\hline Switzerland & 84 & 33 & 6202 & 759.97 & 920.38 \\
\hline $\begin{array}{l}\text { Other America } \\
\text { Countries }\end{array}$ & 84 & 55 & 20424 & 913.54 & 1534.75 \\
\hline USA & 84 & 26 & 4977 & 1001.56 & 1051.07 \\
\hline $\begin{array}{l}\text { Other Asian } \\
\text { Countries }\end{array}$ & 84 & 60 & 4226 & 719.31 & 628.35 \\
\hline Japan & 84 & 4 & 3223 & 435.48 & 411.91 \\
\hline China & 84 & 5 & 2698 & 264.02 & 316.16 \\
\hline Middle East & 84 & 1 & 2346 & 160.17 & 313.16 \\
\hline $\begin{array}{l}\text { African } \\
\text { Countries }\end{array}$ & 84 & 47 & 1600 & 351.75 & 247.57 \\
\hline
\end{tabular}

\section{Table 2}

Average price for hotels category in NPDC

\begin{tabular}{lll}
\hline & $\begin{array}{l}\text { Average price (euro) for peak } \\
\text { season (May, June, July, August) }\end{array}$ \\
\hline Null and 1 star & 48,4444 & 43,4091 \\
2 star & 78,0056 & 63,7955 \\
3 and 4 star & 124,6173 & 96,0125 \\
\hline
\end{tabular}


In this paper, we have used a Matlab program written by ourselves to run the estimation and produce the graphics. The results are presented in the following Tables (Table 3 to Table 6). As aforementioned, there are three models:

1. Model 1 maximizes the expected return for a fixed variance;

2. Model 2 minimizes the risk for a given expected return;

3. Model 3 maximizes the expected return and minimizes the risk for a prechosen direction (with $g=(-V, E))$ and therefore identifies the inefficiency level.

Table 3 demonstrates the results of the mean-augmentation approach (Model 1). Column 2 and 3 shows origins expected overnight stays and standard deviation for the year 2013. Column 4 shows the maximum attainable overnight stays for each origin, Column 5 shows the technical efficiency and the last column gives the rank of each origin according to its performance. For example, for next year, for the given risk level and optimal portfolio weights, NPDC can expect a maximum 43,853 overnight stays from Belgium, being an increase of $24.52 \%$ compared to the past. Meantime, this increase can be as high as $63.19 \%$ for USA, which means that USA as a tourist origin places further from the efficient frontier than Belgium. Therefore, USA performs worse than Belgium in the tourist portfolio of NPDC. Table 4 displays the risk-contraction approach (Model 2). As for Belgium, for the same level of overnight stays, NPDC can reduce the risk, so the average volatility of tourism expenditures, from this origin by $22.9 \%$.

However, if NPDC seeks to rise the overnight stays and at the same time reduce the risk, then the results of DDF approach presented in Table 5 should be considered (Model 3). Taking Belgium for example, for the year 2013, NPDC can expect 35,217 overnight stays from Belgium with a 
standard deviation of 14,665 . But according to the results of our model, NPDC should be able to attract 38,522 overnight stays with a risk level of 13,960; it means NPDC could at the same time improve the return and reduce the instability of Belgium tourists by $9.4 \%$.

For these three models, the UK is the most efficient origin and therefore severs as the benchmark for all the other origins. This can be explained by its geographic localization since the EUROSTAR train line and The Channel Tunnel link the UK and NPDC. The historical and cultural links shared between UK and NPDC is also explanation of this fact. The same explanation can be applied to Belgium. As the middle point between Paris and Brussels, it is not surprising that tourist from Belgium performs very well for NPDC. As for Spain and Italy, their good performance can be explained by the fact that firstly, there is lots of Spanish and Italian former immigrants in the region since the $19^{\text {th }}$ and $20^{\text {th }}$ centuries, lots of family reunion occurs in NPDC; secondly, as a European country, tourists from these two countries know well the tourist monuments and culture attraction in NPDC. As for the tourists from USA, China and Japan, NPDC is just a stop over to visit Paris, Brussels, Amsterdam or Luxembourg. And since the tourists from these countries traditionally do not know the region very well, so the poor performance of these markets is not surprising. This result is very interesting, since in the paper Botti et al. (2012), the authors found USA is quite efficient to France, here the explanation is once more the American tourists who enjoy Paris and other more popular French destinations, may not be familiar with the tourism products of the NPDC.

The region NPDC played a prominent role during the First World War. At any given moment, every community in the Pas-de-Calais had, to a greater or lesser extent, an involvement in the war and considered as a microcosm of the world at war. Therefore, local public authorities of NPDC are hoping to better market the region by developing "Memorial 
Tourism" to commemorate the beginning of the $100^{\text {th }}$ anniversary of the First World War to show case its products to Northern American and Chinese tourists.

As we can see in Table 6, the average performance of the origins is poor. According to the average overall inefficiency score, NPDC can improve $86.53 \%$ of its utility obtained in the tourist sector for the given utility function. And the decomposition results show that among these potential utility improvements, $30.97 \%$ comes from technical inefficiency and 55.55\% comes from allocative inefficiency. There is no origin perfectly satisfy NPDC's preference (The most efficient is the African countries, with an OE equals to $39.17 \%$ ). This result means besides the possible return augmentation and risk contraction, the wrong choice of values of risk aversion is the main source of inefficiency for the region. In order to improve the allocative efficiency, NPDC should guide their tourist policy to change the combination of return and risk for these origins according to region's own preference (utility function). Once all the origins achieve the efficient frontier, NPDC need to move these origins along the frontier to reach the tangent point (maximum utility for NPDC). Optimal portfolio share (PS) for each origin, which allows NPDC to achieve its maximum utility $\left(U^{*}=-240903\right)$ is also reported in Table 6 .

Results of DDF approach and efficiency decomposition are also illustrated in Figure 2, 3 and 4 in the appendix. Figure 2 and Figure 3 present each origin in the mean-variance space and their projection on the efficient frontier. Figure 3 is obtained by omitting England, which is behaving as an outlier from the sample to present a clear representation of the framework. To illustrate the decomposition analysis, the Figure 4 proposes an utility function characterized by a risk aversion equal to 0.01 , few origins and the optimal portfolio (in terms of OE). Shares of origins for this portfolio are reported in Table 8. In Figure 4, two efficient points 
(which represent China and African countries) are very close to the utility function which corresponds to decomposition results in Table 8 ; the AE for these two origins is not far away from null (0.0063 for China, and 0.0191 for African countries).

One potential issue is the sensitivity of our decomposition result since importance of $\mathrm{OE}$ and $\mathrm{AE}$ is related to the risk aversion $\phi$. In order to test the robustness of our result, computed the $\mathrm{OE}, \mathrm{AE}$ for a large range of $\phi$ were computed Since according to the literature the conventional value should range between 0.5 and 10, Figure 5 shows the decomposition of the average efficiency for $\mu=1$ and $\rho \in[0.0110]$. The detail result will be showed in table 7 .

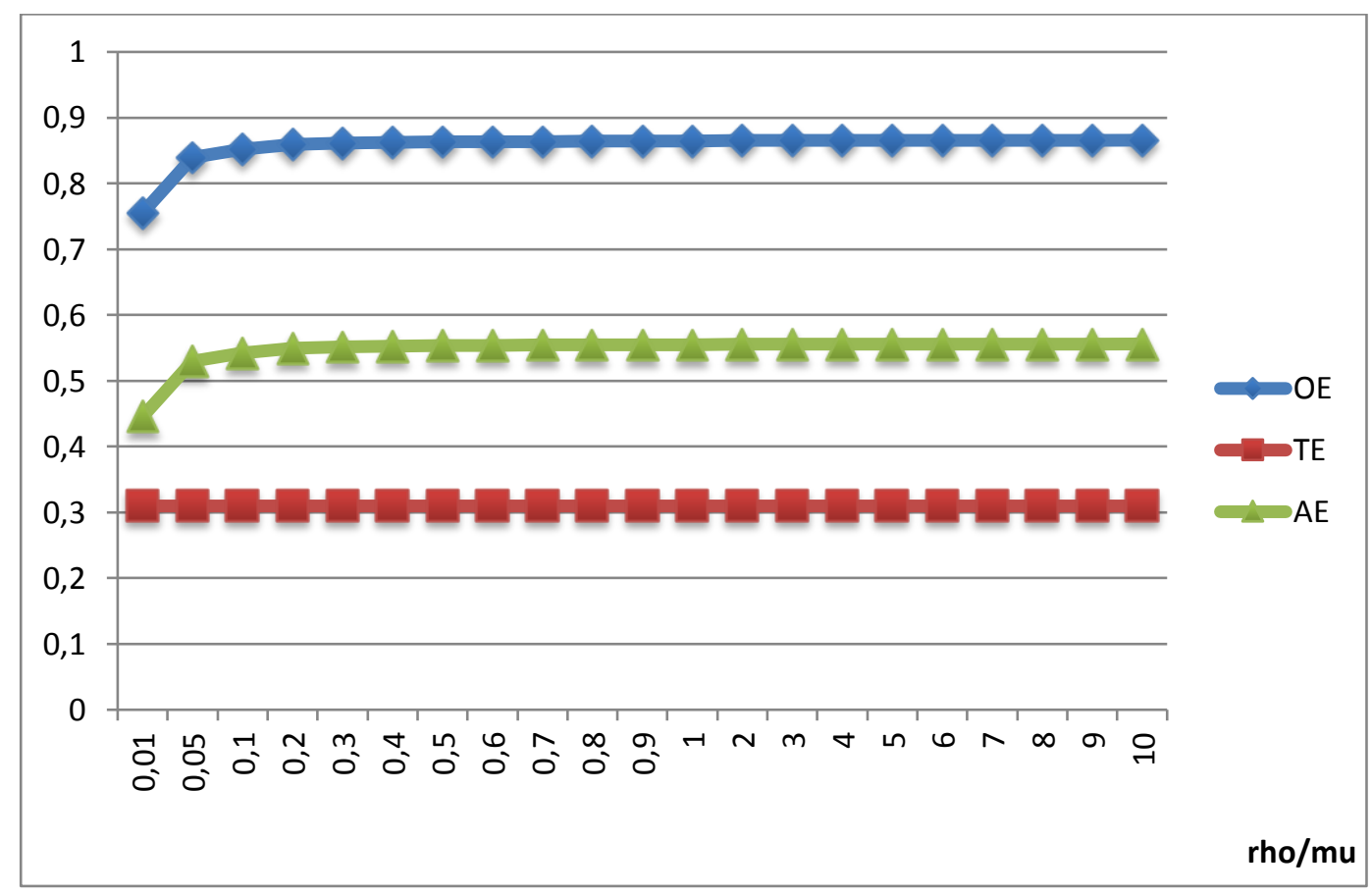

Fig. 5. Evaluation of overall efficiency decomposition for a range of risk aversion

Even as the risk aversion changes, the relative importance of $\mathrm{OE}, \mathrm{PE}$ and $\mathrm{AE}$ remains the same for NPDC. The main resource of inefficiency always comes from AE. This result shows that our conclusion is robust to the different value of $\phi$. 


\section{Conclusion and Future Research}

Efficiency analysis is attracting more and more attention in tourism economic research. The traditional method is data envelopment analysis applied to hotels and restaurants. Researchers often neglect the competition among tourism destinations and the heterogeneity between different tourist origins ${ }^{4}$. In this paper, the model introduced by Botti et al. (2012) is augmented by the inclusion of a utility function which allows for the measurement of not only tourism efficiency by origins but also identification of inefficiency in resource allocation. By relating the Markowitz's Mean-Variance framework and non-parametric frontier estimation method, policy makers are provided with accurate performance indicators for future strategic decision.

Our empirical results clearly show that NPDC has loads to do to improve the performance in tourism sector. The number of overnight stays generated by the tourists neighboring countries (England, Belgium, Spain, Italy) are quite efficient, however, NPDC has to improve its marketing strategies to the market outside of Europe (China, Japan, USA, etc.). The main source of utility inefficiency for NPDC comes from AE, which means the wrong choice of risk and return of the origins, therefore, by applying certain promotion policy (pubs, discount, etc), NPDC can change the proportion of origin's return and variance and try to maximize its preference. Lastly, this region contains many historic and cultural tourism capitals (as Braderie de Lille, Louvre-Lens, Piscine of Roubaix, Fine Art Museum of Lille, Nausicaà, Memorial of Helfaut, etc.), which can provide new sources of tourism receipts if they are well exploited.

\footnotetext{
${ }^{4}$ Even we can use two stage DEA model to identify the influence of tourist nationalities on tourism efficiency, the truncate regression in second stage still suffers lots of defauts ( forme specification, statitifcal reference can only obtained by boot-strap method, the frontier forme did not take into account the influence of environmental variables, etc). The parametric method however can not trait well multioutput problem and the results depends largely the function form pre-supposed.
} 
This kind of methodology can be very useful for territories which have a need to develop their international tourism market and which are characterized by a strong proportion of internal tourism (as NPDC). It is well known in tourism that the international market can provide a better economic contribution than the local market but all the marketing strategies, according to the nationality aimed, are not always efficient.

The other advantage of this methodology is to provide some crucial information about the power of attraction for a given destination according to the tourist's country of origin. A gravitational model, by using bilateral data, gives some important descriptions about this power of attraction. But, the method developed in this present paper provides a new source of information: the potential of output that can be expected and the risk associated. An interesting further research can be to combine these two methodologies (gravitational model and mean-variance analysis) and comparing the different results in order to understand how the international tourism marketing strategy developed by the local authorities can be improved. And another research line reports to the vector $x$ introduced in the theoretical framework of this paper. It should be interesting for policy decision makers to know the composition of this vector i.e. the weight of each funds (here origins) in the optimal portfolio of origins. 


\section{Table 3}

Results of mean Augmentation Approach

\begin{tabular}{|c|c|c|c|c|c|}
\hline \multirow[t]{2}{*}{ Origins } & \multicolumn{5}{|c|}{ Mean Augmentation Approach } \\
\hline & $\begin{array}{l}\text { Expected Over-Night } \\
\text { Stays }\end{array}$ & Std & $\begin{array}{c}\text { Maximum Attainable Over- } \\
\text { Night Stays }\end{array}$ & PE(TE) & Rank \\
\hline United Kingdom & 136932 & 61376 & 136932 & 0,000 & 1 \\
\hline Other European Countries & 13519 & 5081 & 14972 & 0,1075 & 2 \\
\hline Spain & 4480 & 1525 & 5276 & 0,1778 & 3 \\
\hline Belgium & 35217 & 14665 & 43853 & 0,2452 & 4 \\
\hline Italy & 6759 & 2820 & 8831 & 0,3065 & 5 \\
\hline Japan & 1306 & 625 & 1772 & 0,3567 & 6 \\
\hline Germany & 14509 & 6610 & 19695 & 0,3574 & 7 \\
\hline Netherlands & 11393 & 5313 & 15613 & 0,3704 & 8 \\
\hline African Countries & 1055 & 446 & 1533 & 0,4529 & 9 \\
\hline USA & 3005 & 1462 & 4903 & 0,6319 & 10 \\
\hline Other Asian Countries & 2158 & 1086 & 3737 & 0,7318 & 11 \\
\hline Switzerland & 2280 & 1514 & 5058 & 1,2186 & 12 \\
\hline China & 792 & 558 & 1957 & 1,4714 & 13 \\
\hline Other America Countries & 2741 & 3427 & 10500 & 2,8312 & 14 \\
\hline Middle East & 481 & 547 & 1918 & 2,992 & 15 \\
\hline
\end{tabular}


Table 4

Results of risk contraction approach

\begin{tabular}{|c|c|c|c|c|c|}
\hline \multirow[t]{2}{*}{ Origins } & \multicolumn{5}{|c|}{ Risk Contraction Approach } \\
\hline & $\begin{array}{c}\text { Expected Over-Night } \\
\text { Stays }\end{array}$ & Std & $\begin{array}{c}\text { Minimum Attainable } \\
\text { Std }\end{array}$ & PE(TE) & Rank \\
\hline United Kingdom & 136932 & 61376 & 61376 & 0 & 1 \\
\hline Other European Countries & 13519 & 5081 & 4544 & 0,2004 & 2 \\
\hline Belgium & 35217 & 14665 & 12877 & 0,229 & 3 \\
\hline Spain & 4480 & 1525 & 1323 & 0,2467 & 4 \\
\hline African Countries & 1055 & 446 & 354 & 0,3716 & 5 \\
\hline Germany & 14509 & 6610 & 4913 & 0,4475 & 6 \\
\hline Italy & 6759 & 2820 & 2091 & 0,45 & 7 \\
\hline Netherlands & 11393 & 5313 & 3755 & 0,5004 & 8 \\
\hline Middle East & 481 & 547 & 348 & 0,596 & 9 \\
\hline Japan & 1306 & 625 & 396 & 0,5988 & 10 \\
\hline China & 792 & 558 & 348 & 0,6115 & 11 \\
\hline USA & 3005 & 1462 & 863 & 0,652 & 12 \\
\hline Other Asian Countries & 2158 & 1086 & 614 & 0,6804 & 13 \\
\hline Switzerland & 2280 & 1514 & 649 & 0,8163 & 14 \\
\hline Other America Countries & 2741 & 3427 & 784 & 0,9477 & 15 \\
\hline
\end{tabular}


Table 5

Results of mean augmentation and risk contraction approach

\begin{tabular}{|c|c|c|c|c|c|c|}
\hline \multirow[t]{2}{*}{ Origins } & \multicolumn{6}{|c|}{ DDF Approach } \\
\hline & $\begin{array}{l}\text { Expected Over- } \\
\text { Night Stays }\end{array}$ & Std & $\begin{array}{c}\text { Maximum } \\
\text { Attaintable Over-Night } \\
\text { Stays }\end{array}$ & $\begin{array}{c}\text { Minimum } \\
\text { Attaintable Std }\end{array}$ & PE(TE) & Rank \\
\hline United Kingdom & 136932 & 61376 & 136932 & 61376 & 0,0000 & 1 \\
\hline Other European Countries & 13519 & 5081 & 14471 & 4899 & 0,0704 & 2 \\
\hline Spain & 4480 & 1525 & 4880 & 1455 & 0,0895 & 3 \\
\hline Belgium & 35217 & 14665 & 38522 & 13960 & 0,0938 & 4 \\
\hline Germany & 14509 & 6610 & 17269 & 5948 & 0,1902 & 5 \\
\hline Italy & 6759 & 2820 & 8046 & 2537 & 0,1903 & 6 \\
\hline Netherlands & 11393 & 5313 & 13910 & 4690 & 0,2209 & 7 \\
\hline African Countries & 1055 & 446 & 1292 & 393 & 0,2244 & 8 \\
\hline USA & 3005 & 1462 & 4044 & 1183 & 0,3459 & 9 \\
\hline Japan & 1306 & 625 & 1761 & 505 & 0,3481 & 10 \\
\hline Other Asian Countries & 2158 & 1086 & 2979 & 855 & 0,3804 & 11 \\
\hline China & 792 & 558 & 1218 & 379 & 0,5380 & 12 \\
\hline Switzerland & 2280 & 1514 & 3524 & 1020 & 0,5457 & 13 \\
\hline Middle East & 481 & 547 & 767 & 348 & 0,5960 & 14 \\
\hline Other America Countries & 2741 & 3427 & 4968 & 1484 & 0,8125 & 15 \\
\hline
\end{tabular}


Table 6

Decomposition of efficiency score for DDF approach

\begin{tabular}{lcccc}
\hline & OE & PE(TE) & AE & PS \\
\hline $\begin{array}{l}\text { Other European } \\
\text { Countries }\end{array}$ & 0,9948 & 0,0704 & 0,9244 & 0.00000 \\
Germany & 0,9969 & 0,1902 & 0,8067 & 0.00000 \\
Belgium & 0,9993 & 0,0938 & 0,9055 & 0.00000 \\
Spain & 0,9463 & 0,0895 & 0,8568 & 0.00000 \\
Italy & 0,9840 & 0,1903 & 0,7937 & 0.00000 \\
Netherlands & 0,9953 & 0,2209 & 0,7744 & 0.00000 \\
United Kingdom & 0,9999 & 0,0000 & 0,9999 & 0.00000 \\
Switzerland & 0,9465 & 0,5457 & 0,4008 & 0.00000 \\
Other America & 0,9895 & 0,8125 & 0,1770 & 0.00053 \\
Countries & 0,9423 & 0,3459 & 0,5965 & 0.00000 \\
USA & 0,8961 & 0,3804 & 0,5157 & 0.00000 \\
Other Asian Countries & 0,6889 & 0,3481 & 0,3408 & 0.23423 \\
Japan & 0,6110 & 0,5380 & 0,0729 & 0.24089 \\
China & 0,5963 & 0,5960 & 0,0003 & 0.16720 \\
Middle East & 0,3917 & 0,2244 & 0,1673 & 0.35716 \\
African Countries & 0,8653 & 0,3097 & 0,5555 & $U^{*}=-240903$ \\
\hline \multicolumn{1}{c}{ Mean } & & & &
\end{tabular}


Table 7

Robust test for the sensibility of OE decomposition

\begin{tabular}{cccc}
\hline $\mathbf{r h o} / \mathbf{m u}$ & $\mathbf{O E}$ & $\mathbf{P E}(\mathbf{T E})$ & $\mathbf{A E}$ \\
\hline $\mathbf{0 , 0 1}$ & 0,755396 & 0,309748 & 0,445649 \\
$\mathbf{0 , 0 5}$ & 0,839618 & 0,309748 & 0,529870 \\
$\mathbf{0 , 1}$ & 0,852454 & 0,309748 & 0,542707 \\
$\mathbf{0 , 2}$ & 0,859117 & 0,309748 & 0,549369 \\
$\mathbf{0 , 3}$ & 0,861376 & 0,309748 & 0,551628 \\
$\mathbf{0 , 4}$ & 0,862513 & 0,309748 & 0,552765 \\
$\mathbf{0 , 5}$ & 0,863198 & 0,309748 & 0,553450 \\
$\mathbf{0 , 6}$ & 0,863655 & 0,309748 & 0,553907 \\
$\mathbf{0 , 7}$ & 0,863982 & 0,309748 & 0,554234 \\
$\mathbf{0 , 8}$ & 0,864228 & 0,309748 & 0,554480 \\
$\mathbf{0 , 9}$ & 0,864419 & 0,309748 & 0,554671 \\
$\mathbf{1}$ & 0,864572 & 0,309748 & 0,554824 \\
$\mathbf{2}$ & 0,865262 & 0,309748 & 0,555514 \\
$\mathbf{3}$ & 0,865492 & 0,309748 & 0,555744 \\
$\mathbf{4}$ & 0,865607 & 0,309748 & 0,555859 \\
$\mathbf{5}$ & 0,865676 & 0,309748 & 0,555929 \\
$\mathbf{6}$ & 0,865722 & 0,309748 & 0,555975 \\
$\mathbf{7}$ & 0,865755 & 0,309748 & 0,556008 \\
$\mathbf{8}$ & 0,865780 & 0,309748 & 0,556032 \\
$\mathbf{9}$ & 0,865799 & 0,309748 & 0,556052 \\
$\mathbf{1 0}$ & 0,865815 & 0,309748 & 0,556067 \\
\hline & & &
\end{tabular}




\section{Appendix}

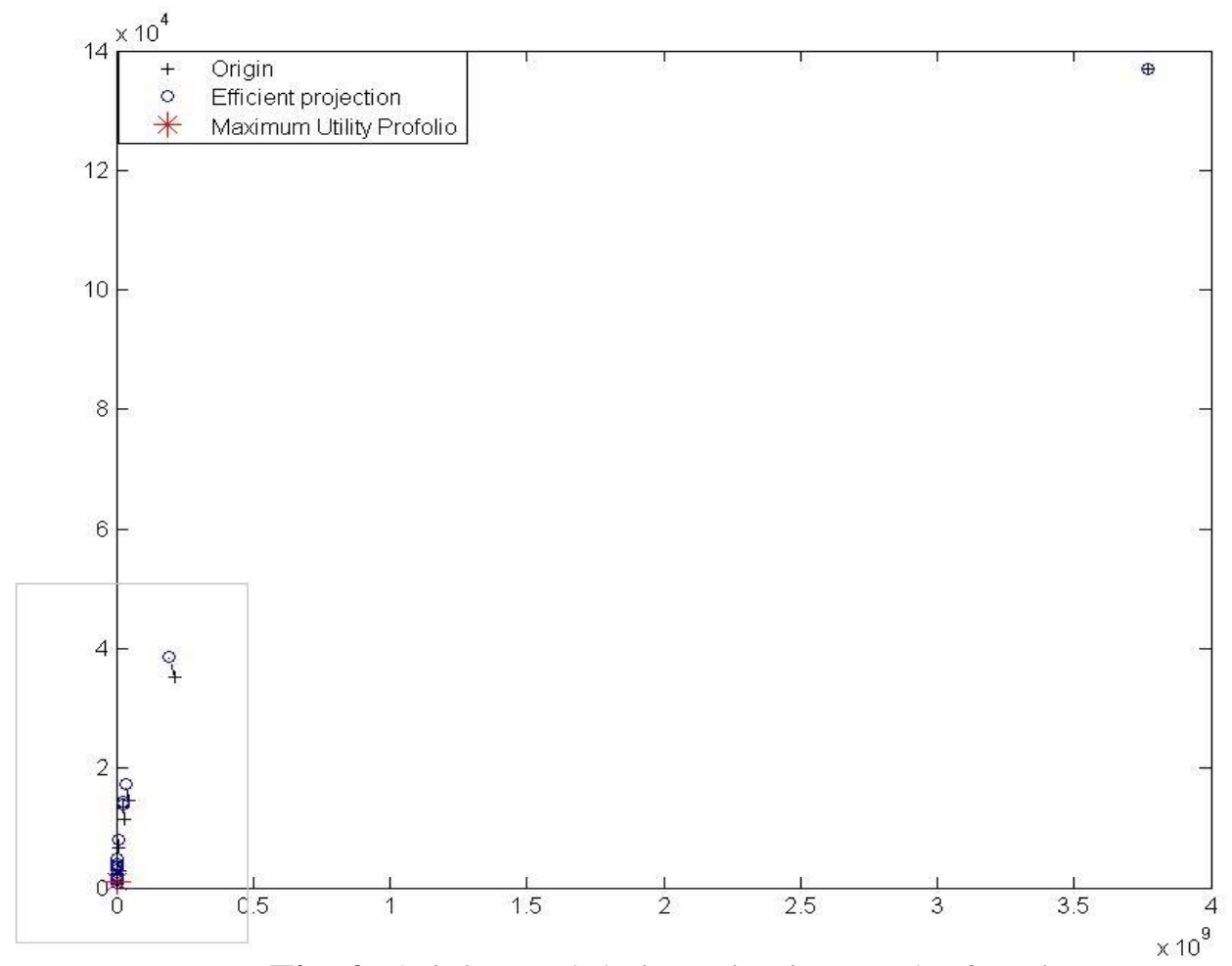

Fig. 2. Origins and their projection on the frontier

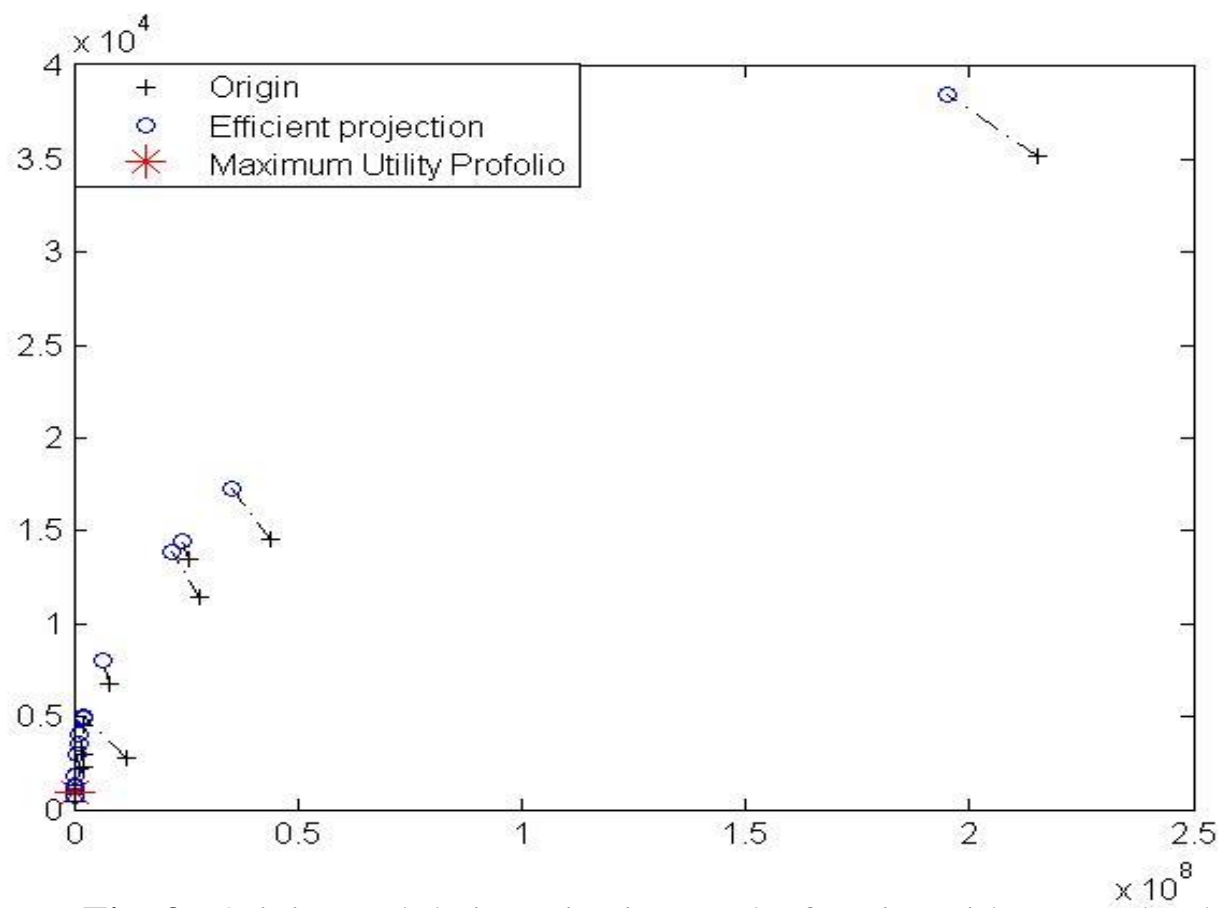

Fig. 3. Origins and their projection on the frontier without England 


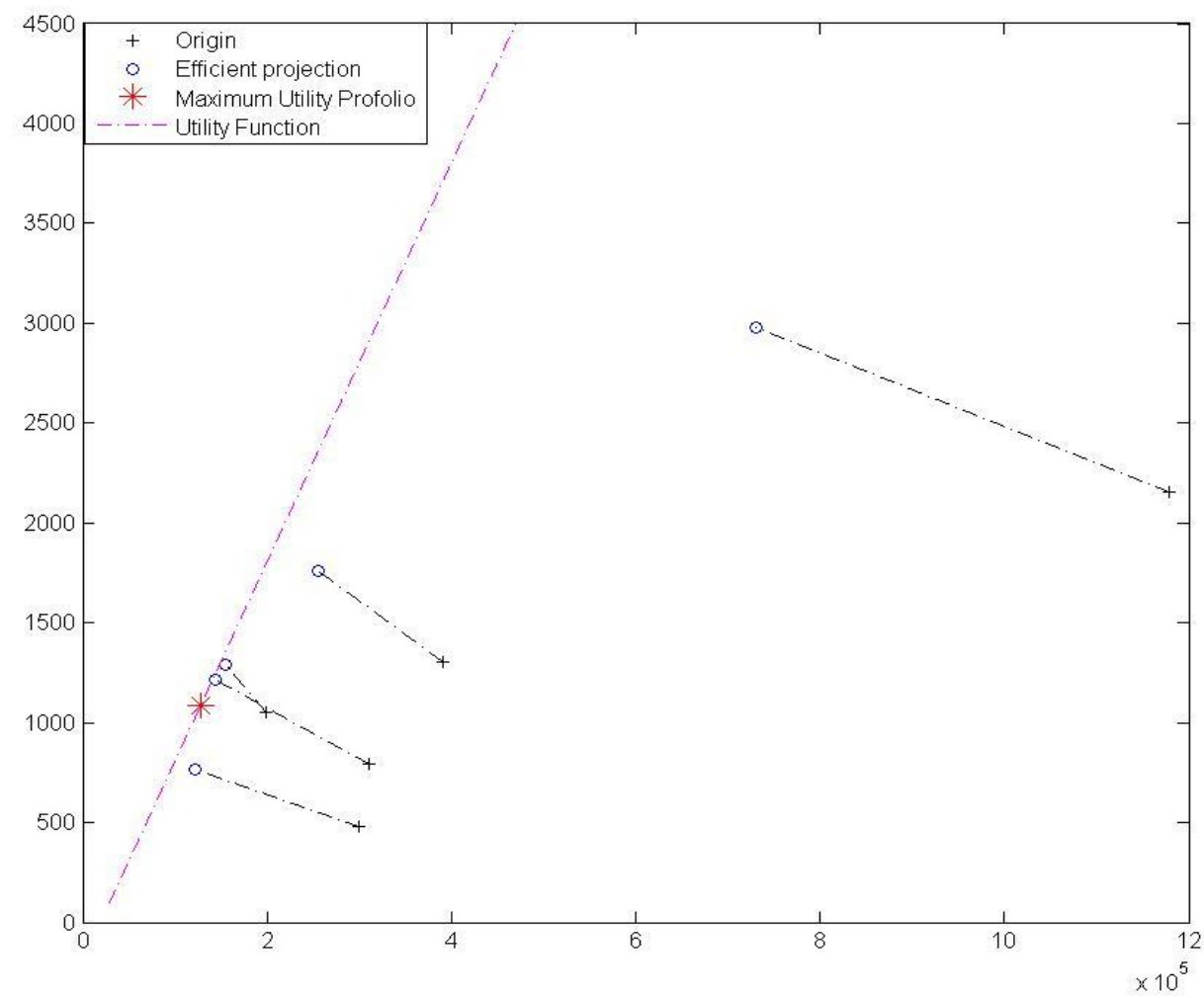

Fig. 4. Illustration of Utility function and Overall efficiency decomposition with risk aversion $\phi=0.01$ 


\section{Table 8}

Decomposition of efficiency score for DDF approach, with risk aversion $\phi=0.01$

\begin{tabular}{lcccc}
\hline \multicolumn{1}{c}{ Origins } & OE & PE(TE) & AE & PS \\
\hline $\begin{array}{l}\text { Other European } \\
\text { Countries }\end{array}$ & 0.8998 & 0.0704 & 0.8293 & 0.00000 \\
Germany & 0.9353 & 0.1902 & 0.7450 & 0.00000 \\
Belgium & 0.9677 & 0.0938 & 0.8739 & 0.00000 \\
Spain & 0.6698 & 0.0895 & 0.5803 & 0.00000 \\
Italy & 0.8410 & 0.1903 & 0.6507 & 0.00000 \\
Netherlands & 0.9217 & 0.2209 & 0.7008 & 0.00000 \\
United Kingdom & 0.9928 & 0.0000 & 0.9928 & 0.00000 \\
Switzerland & 0.8113 & 0.5457 & 0.2656 & 0.00000 \\
Other America & 0.9528 & 0.8125 & 0.1402 & 0.00934 \\
Countries & 0.7456 & 0.3459 & 0.3998 & 0.00000 \\
USA & 0.6767 & 0.3804 & 0.2963 & 0.00737 \\
Other Asian Countries & 0.4615 & 0.3481 & 0.1134 & 0.26922 \\
Japan & 0.5444 & 0.5380 & 0.0063 & 0.20750 \\
China & 0.6672 & 0.5960 & 0.0712 & 0.01597 \\
Middle East & 0.2435 & 0.2244 & 0.0191 & 0.49059 \\
African Countries & 0.3097 & 0.4456 & $U^{*}=-38998.5$ \\
\hline Mean & & & &
\end{tabular}




\section{References}

Anderson, R. I., Fok, R., and Scott, J. (2000). "Hotel industry efficiency: an advanced linear programming examination". American Business Review, 18(1), 40-48.

Assaf, A., Barros, C.P. and Machado, L.P. (2011). "The future outlook for Portuguese travel agents". Tourism Economics, 17(2), 405-423.

Assaf, A.G. (2012) "Benchmarking the Asia Pacific tourism industry: a Bayesian combination of DEA and stochastic frontier". Tourism Management, 33(5), 1122-1127.

Banker, R.D., Charnes, A. and Cooper, W.W. (1984). "Some Models for Estimating Technical and Scale Inefficiencies in Data Envelopment Analysis". Management Science, 30, 1078-1092.

Banker, R. D., and Morey, R. C. (1986). "Efficiency analysis for exogenously fixed inputs and outputs". Operations Research, 34(4), 513521.

Barros, C. P. (2004). "A Stochastic Cost Frontier in the Portuguese Hotel Industry". Tourism Economics, 10(2), 177-192.

Barros, C. P., and Alves, F. P. (2004). "Productivity in the tourism industry". International Advances in Economic Research, 10(3), 215-225.

Barros, C. P., and Santos, C. (2006). "The measurement of efficiency in Portuguese hotels using Data Envelopment Analysis". Journal of Hospitality and Tourism Research, 30(3), 378-400.

Barros, C.P., Botti, L., Peypoch, N., Robinot, E., Solonandrasana, B. and Assaf, A.G. (2011) "Performance of French destinations: Tourism attraction perspectives". Tourism Management, 32(1), 141-146.

Bosetti, V., Cassinelli, M. and Lanza, A. (2006). "Benchmarking in tourism destination, keeping in mind the sustainable paradigm". Nota di Lavoro 12.2006, Fondazione Eni Enrico Mattei.

Botti, L., Peypoch, N., Robinot, E. and Solonandrasana, B. (2009). "Tourism Destination Competitiveness: the French regions case". European Journal of Tourism Research, 2, 5-24.

Botti, L., Goncalves, O., and Ratsimbanierana. H. (2012). "French Destination Efficiency: A Mean-Variance Approach". Journal of Travel Research, 51(2), 115-129.

Brida, J. G. and Risso, W. A. (2009). "Tourism as a factor of long-run economic growth: an empirical analysis for Chile". European Journal of Tourism Research, 2(2), 178-185. 
Briec, W., Kerstens, K. and Lesourd. J. B. (2004). "Single Period Markowitz Portfolio Selection, Performance Gauging and Duality: A Variation on the Luenberger Shortage Function". Journal of Optimization Theory and Applications, 120(1), 1-27.

Briec, W., Kerstens, K. and Jokung, O. (2007). "Mean-VarianceSkewness Portfolio Performance Gauging: A General Shortage Function and Dual Approach". Management Science, 53(1), 135-49.

Charnes, A., Cooper, W.W. and Rhodes, E. (1978). "Measuring the efficiency of decision making units". European Journal of Operational Research, 2(6), 49-444.

Chambers, R.G, Chung, Y. and Färe, R. (1998). "Profit, directional distance functions, and Nerlovian efficiency". Journal of Optimization Theory and Applications, 98, 351-364.

Chiang, W., Tsai, M., and Wang, L. S. (2004). "A DEA evaluation of Taipei hotels". Annals of Tourism Research, 31(3), 712-715.

Daniels, M. J. (2004). "Beyond Input-Output Analysis: Using Occupation-Based Modeling to Estimate Wages Generated by a Sport Tourism Event". Journal of Travel Research, 43(1), 75.

Färe, R., and S. Grosskopf. (2000). "Theory and Application of Directional Distance Functions". Journal of Productivity Analysis, 13, 93103.

Hwang, S. N., \& Chang, T. Y. (2003). "Using Data Envelopment Analysis to Measure Hotel Managerial Efficiency Change in Taïwan". Tourim Management, 24(4), 357-369.

Hruschka, H. (1986). "Ansätze der Effizienmessung von Betrieben". Journal für Betriebswirtschaft, 36(2), 76-85.

Kennedy, V. (1998). "Risk Management in the Irish Tourism Industry: The contribution of a Portfolio Investment Approach". Tourism Management, 19(2), 119-126.

Köksal, C. D., and Aksu, A. A. (2007). "Efficiency evaluation of Agroup travel agencies with data envelopment analysis (DEA): A case study in the Antalya region, Turkey". Tourism Management, 28(3), 830-834.

Luenberger, D. G. (1992). "Benefit Function and Duality". Journal of Mathematical Economics, 21, 461-81.

Markowitz, H. (1952). "Portfolio Selection". Journal of Finance, 7, 7791.

Markowitz, H. (1959). "Portfolio Selection: Efficient Diversification of Investments". New York: John Wiley. 
Morey, R. C. and Dittman, D. A. (1995). "Evaluating a hotel GM's performance: a case study in benchmarking". Cornell Hotel Restaurant \& Administration Quarterly, 36(5), 30-35.

Morey, M. R., and Morey, R. C. (1999). "Mutual Fund Performance Appraisals: A Multi-Horizon Perspective with Endogenous Benchmarking". Omega, 27, 241-58.

Perrigot R., Cliquet G. and Piot-Lepetit I. (2009), "Plural form Chain and Efficiency: Insights from the French Hotel Chains and the DEA Methodology". European Management Journal, 27, 268-280.

Peypoch, N. and Solonandrasana, B. (2006). "A Note on Technical Efficiency in Tourism Industry". Tourism Economics, 12(4), 653-57.

Peypoch, N. (2007). "On Measuring Tourism Productivity". Asia Pacific Journal of Tourism Research, 12(3), 237-44.

Peypoch, N. (2007). "Productivité du Secteur Touristique Français : Une comparaison inter-régionale". Économie et Prévision, Programme National Persée, 177(1), 65-76.

Ratsimbanierana, H., Sbai, S. and Stenger, A. (2013). "Moroccan tourist portfolio efficiency with the mean-variance approach". European Journal of Tourism Research, 6(2), 122-131.

Seiford, L. M. (1996). "Data Envelopment Analysis: The Evolution of the State of the Art (1978-1995)". Journal of Productivity Analysis, 7(2/3), 99-138

Tang, C. F. and Tan, E. C. (2013). "How stable is the tourism-led growth hypothesis in Malaysia? Evidence from disaggregated tourism markets". Tourism Management, 37, 52-57.

Uysal, E., F. Trainer Jr., and Reiss, J. (2001). "Revisiting MeanVariance Optimization". Journal of Portfolio Management, 27(4), 71-81. 